\title{
Environmental Physics: An Introduction
}

\author{
Matthew N. O. Sadiku ${ }^{1}$, Tolulope J. Ashaolu' ${ }^{2}$, Abayomi Ajayi-Majebi, ${ }^{3}$ and Sarhan M. Musa1
}

${ }^{1}$ Roy G. Perry College of Engineering, Prairie View A\&M University, Prairie View, TX, USA

${ }^{2}$ College of Food Science, Southwest University, Beibei, Chongqing, China

${ }^{3}$ Department of Manufacturing Engineering, Central State University, Wilberforce, OH, USA

E-mail: sadiku@ieee.org; ashaolut@gmail.com; ajayi-majebi@centralstate.edu; smmusa @pvamu.edu

*corresponding author details: Professor Matthew N. O. Sadiku; sadiku@ieee.org

\begin{abstract}
Physics is essential for understanding natural phenomena. It provides a basis for understanding the impact of humans on the environment. This understanding is essential for environmental stewardship. Environmental physics is essentially the applications of the principles of physics to environmental processes and problems. Environmental physicists use the principles and techniques of physics to study the earth's environment. They have made significant contributions to understanding global climate change and other environmental issues. This paper provides an introduction to environmental physics.
\end{abstract}

Keywords: environmental physics; environmental physicists; environmental science; natural science

\section{INTRODUCTION}

In a modern society, it is easy to forget that our society depends largely on the environmental processes that govern our world. The basis of our economy depends on the soils that sustain our agriculture, the rivers that provide our water, the minerals that provide the raw materials for the goods we consume, and the plants and animals that serve as our food [1]. Human inventiveness has introduced chemicals and materials into the environment.

Environmental problems arise from interaction between man and nature. We live in an age where the greatest threat to our future is not war, but climate change. Scientists and engineers across the world are working together to solve this looming environmental catastrophe [2].

Physics has always been concerned with understanding the natural environment. The word "environment" commands a very broad meaning and it includes air, land and water, plant and animal life including human life. It may be regarded as the medium in which any entity finds itself. Every environmental issue can be represented, explained, and resolved using energy and matter fundamentals. Matter refers to anything that has both mass and volume, and it appears in three basic phases: solids, liquids, and gases. Energy lies at the heart of environmental issues. Understanding the forces and laws that underpin the interactions of matter and energy form a major part of environmental physics [3].

\section{CONCEPT OF ENVIRONMENTAL PHYSICS}

Physics is the study of the forces and laws of nature. It is the branch of physics concerned with the measurement and analysis of interactions between organisms and their environment. It is often regarded as the fundamental science, because all other natural sciences (such as astrophysics, geophysics, chemical physics, and biophysics) apply the principles and laws of physics.
Physics relies heavily on mathematics as the tool for problem formulation and quantification of principles. Physical principles are largely derived from direct observation and experimentation of nature. Physics is a broad field including mechanics, optics, electricity, magnetism, electromagnetics, thermodynamics, and quantum mechanics.

Environment may be regarded as the medium in which any entity finds itself. Environmental physics is essentially is a physical science. It applies the theoretical and experimental techniques of optical, surface, and condensed matter physics to the environmental problems facing us today. It embraces the following concepts: human environment and survival physics, built environment, urban environment, renewable energy, remote sensing, weather, climate change, environmental health, and environmental control [4].

It deals with atmospheric science, pollution detection and remediation, dynamical processes at land-water, colloidal science, and biological effects of pollution, and bioremediation science, weather forecasting, and environmental control. To fully understand the complexities of the environment and to address environmental problems effectively, the underlying physics must be combined with biology, chemistry, and geology. Effective management of human interaction with an environmental system requires simultaneous progress on several fronts [5]. Figure 1 illustrates the field of environmental physics [6].

\section{ENVIRONMENTAL PHYSICISTS}

A physicist is someone who studies the forces, laws, and behavior of nature to understand how things work. Most physicists use math to describe theories and processes, use complex calculations, use software packages to simulate physical systems, observe and measure physical phenomena in laboratories, conduct research and development, and share their research results with others at conferences. 
Other physicists with advance degrees teach and do research as faculty members at colleges and universities.

Environmental physicists need a good understanding of basic physics, particularly the properties of matter, heat, thermodynamics, and fluid dynamics. They apply physical principles to environmental problems. They seek to understand the mechanisms by which environmental change impacts humans and other organisms. They need a sound understanding of basic physics, properties of matter, thermodynamics, and fluid dynamics. They may have careers in climate modeling, pollution control, energy conservation, renewable energy, and waste disposal Aspiring environmental physicists may also consider specializing in condensed matter physics, electronics, ecology, environmental assessment, and environmental biology. Environmental jobs are increasing in demand [7]. Figure 2 shows some environmental physicists at work [8].

The skills expected of environmental physics graduates include [9]:

- Apply physical principles to problems and formulate solutions

- Integrating theoretical approaches

- Advanced mathematical ability

- Team-based research and ability to work in multi-disciplinary groups

- Design and execute experiments

- Write technical reports and project proposals relevant to given audience

- Demonstrate ethical scientific behavior

- Utilize qualitative and quantitative analysis and problem solving

- Geographic Information Systems (GIS) and Remote Sensing (RS) for solving problems in the environmental sciences

- Qualitative and quantitative approaches for environmental impact assessments \& audits

- Conduct experiments, take measurements, interpret data, and use computers for environmental modeling.

Although the duties of an environment physicist vary from job to job, the following duties are typical [10]:

- Review research and literature relating to current discoveries in the field

- Use computer modeling to predict and gather data about potential solutions

- Document experimental results in a clear and effective manner

- Develop scientific theories and models to explain the properties of the natural world

- Write proposals and apply for research grants

- Present research findings at scientific conferences and lectures

- Use knowledge to develop new devices, processes, and other practical applications

- Foster a positive and safe work environment

- Supervise fieldwork (survey, site recording, testing, monitoring, and data integrity) of multiple field crews

- Communicate with internal stakeholders regarding marketing, intellectual property, and engineering

- Communicate with stakeholders through field status reports and presentation of team findings

\section{APPLICATIONS}

Environmental physics can be applied to a number of atmospheric, oceanographic, Earth-system, and solar-terrestrial situations. It may be conceived as the physics connected with analyzing and mitigating environmental problems. Physics plays a broad role, contributing directly to energy production and environmental projects and indirectly through basic research. It is indispensable in addressing the challenge of making a hydrogen economy safe and affordable. Alternative forms of energy production include nuclear power (both nuclear fission and nuclear fusion) and renewable energy (in many forms, including wind, hydropower, photovoltaic cells, and solar thermal energy). Research and development efforts on these alternative technologies are under way around the world [5].

\section{CHALLENGES}

Environmental sciences are not usually provided with real laboratories where theories can be tested against experiments, since phenomena often take place only once and cannot be reproduced. The lack of a common language is often a barrier to progress in interdisciplinary subjects such as environmental physics. It is difficult for a physicist with no biological training to communicate with an ecologist.

\section{CONCLUSION}

Environmental physics is basically the application of principles of physics to problems in the environment. Physics is the most basic natural science and considers physical systems ranging in size from nuclei, to atoms, to the cosmos. It is an extremely broad field, with many sub-fields. environmental physics has expanded rapidly, driven by concerns over increasing global carbon dioxide concentrations and changing climate. It increases the awareness of human interactions with the planet. More information about environmental physics can be found in the books in [11-25].

\section{REFERENCES}

[1] "Course Syllabus: BIOL 2650: Environmental Biology," https://www.csustan.edu/sites/default/files/groups /Department\%20of\%20Biological\%20Sciences/doc uments/syllabi/spring_2013/biol/biol2650.001.pdf

[2] P. Nair, "An introduction to the field of environmental physics," August 2020, ttps://ysjournal.com/anintroduction-to-the-field-of-environmental-physics

[3] Daniel A. Vallero,

"Chapter 2: Fundamentals of environmental physics" in Environmental Contaminations, 2004.

[4] "Form six environmental physics," https://msomiexpress.wordpress.com/2019/08/ 03/form-six-environmental-physics

[5] National Research Council, "The environment, " Physics in a New Era: An Overview. Washington, DC: The National Academies Press, chapter 7, 2001.

[6] E. Boeker, R. V. Grondelle, and P. Blankert, "Environmental physics as a teaching concept," European Journal of Physics, July 2003.

[7] “What is a physicist?" Unknown Source

[8] "Environmental physics," https://www.utsc.utoronto.ca/admissions/progra ms/environmental-physics

[9] "Career options after environmental physics," https://utsc.utoronto.ca/aacc/career-optionsafter-environmental-physics

[10] "What is a physicist?" https://www.environmentalscience.org/career/phys icist\#: :text=Environmental\%20physicists\%20apply $\% 20$ physical $\% 20$ principles,are $\% 20$ better $\% 20$ for\%2 0the\%20environment.\&text=Geophysicists\%20also \%20work\%20on\%20geothermal,20power. 
[11] V. Faraoni, Exercises in Environmental Physics. Springer, 2006

[12] P. Hughes and N.J. Mason, Introduction to Environmental Physics: Planet Earth, Life and Climate. London, UK: CRC Press, 2014.

[13] Calvin W. Rose, An Introduction to the Environmental Physics of Soil, Water and Watersheds. Cambridge University Press, 2012.

[14] E. Boeker and R. V, Grondelle, Environmental Physics: Sustainable Energy and Climate Change. John Wiley \& Sons, 4th edition, 2013.

[15] A. W. Brinkman, Physics of the Environment. Imperial College Press, 2008.

[16] C. Smith, Environmental Physics. New York: Routledge, 2004.

[17] N. Mason and P. Hughes: Introduction to Environmental Physics: Planet Earth, Life and Climate. Taylor and Francis, 2001.

[18] D. Hillel, Environmental Soil Physics. San Diego, CA: Academic Press, 2003.

[19] K. Forinash, Foundations of Environmental Physics: Understanding Energy Use and Human Impacts. Washington DC: Island Press, 2010.

[20] P. Singh and T. A. Wani, Basic Environmental Physics. Pragati Prakashan, 2016.

[21] Encyclopaedia of Introduction to Environmental Physics: Planet Earth, Life and Climate (4 Volumes). Hillingdon, UK: Publisher Koros Press Limited, 2015.

[22] R. E Robson and D. Blake, Physical Principles of Meteorology and Environmental Physics: Global, Synoptic and Micro Scales. World Scientific Publishing, 2008.

[23] F. Borghese, P. Denti, and R. Saija, Scattering from Model Nonspherical Particles: Theory and Applications to Environmental Physics. Springer, 2007.

[24] D. Hillel, Environmental Soil Physics: Fundamentals, Applications, nd Environmental Considerations. Academic Press, 2004.

[25] J. L. Monteith and M. H. Unsworth, Principles of Environmental Physics. Elsevier, 4th edition, 2013.

\section{ABOUT AUTHORS}

Matthew N.o. Sadiku is a professor emeritus in the Department of Electrical and Computer Engineering at Prairie View A\&M University, Prairie View, Texas. He is the author of several books and papers. His areas of research interests include computational electromagnetics and computer networks. He is a fellow of IEEE.

Tolulope J. Ashaolu is a researcher at Southwest University. He is the author of several papers and a book. His research interests include functional foods and food microbiology.

Abayomi Ajayi-Majebi is a professor in the Department of Manufacturing Engineering at Central State University in Wilberforce, Ohio. In 2015 he was honored by the White House as a Champion of Change for his significant contributions to the engineering education of minority students. He is a senior member of both the Society of Manufacturing Engineers and the American Society for Quality.

Sarhan M. Musa is a professor in the Department of Electrical and Computer Engineering at Prairie View A\&M University, Prairie View, Texas. He has been the director of Prairie View Networking Academy, Texas, since 2004. He is an LTD Sprint and Boeing Welliver Fellow. His areas of research interests include computational.

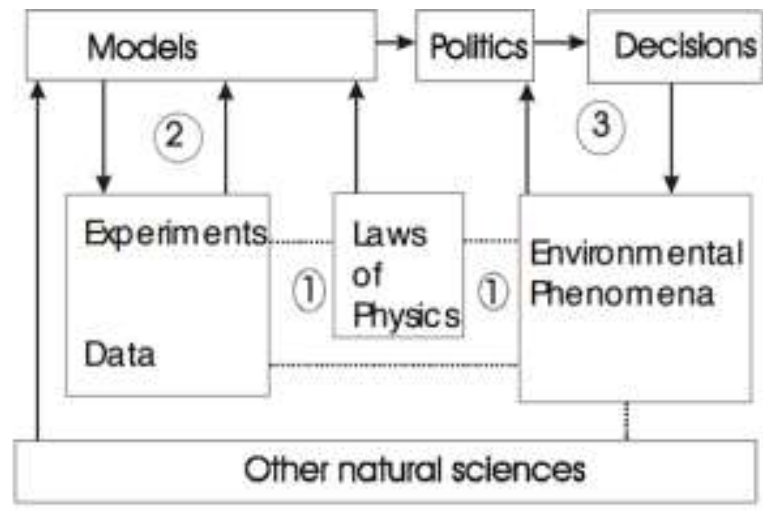

FIGURE 1: The field of environmental physics [6].

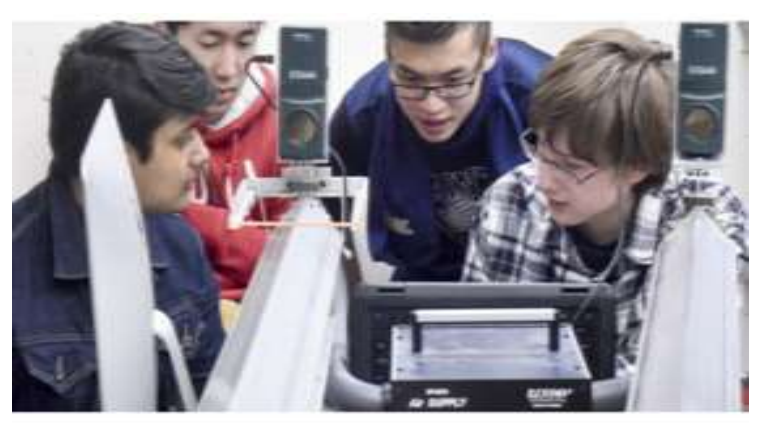

FIGURE 2: Some environmental physicists at work [8] 